\title{
O brincar como intervenção pedagógica nos transtornos do espectro do autismo
}

\section{Playing as a pedagogical intervention on the disorders of the autism spectrum}

\author{
${ }^{1}$ Maria Alina Gusmão Alves alina.gusmao@gmail.com \\ ${ }^{2}$ Marcelo Paraiso Alves
}

\section{RESUMO}

O presente trabalho se refere às investigações de inclusão escolar de crianças nos Transtornos do Espectro do Autismo (TEA) no contexto da educação infantil. O objetivo da pesquisa é investigar o brincar como uma metodologia de ensino e aprendizagem para o aluno no TEA dentro da educação infantil.. O percurso metodológico se desenvolveu por intermédio da revisão de literatura nas bases de dados da ScIELO e do LILACS. Os trabalhos investigados foram artigos selecionados publicados em português no período compreendido entre 2010 e 2015, cujos indexadores foram: autismo, brincar, inclusão escolar e educação infantil. Diante do levantamento realizado foi possível perceber que não há um número significativo de trabalhos que especificamente discutam o brincar como uma ação para a inclusão de alunos no TEA em turmas de educação infantil. E, decorrente dos dados encontrados, percebemos que no atual cenário escolar se fazem necessárias materiais e práticas pedagógicas que apoiem a pratica docente na inclusão de alunos no TEA na educação infantil.

Palavras-chave: Transtornos do Espectro do Autismo; Inclusão; Brincar, Educação Infantil.

\section{ABSTRACT}

The present work refers to the investigations of school inclusion of children in the autism spectrum disorders in the context of child education (ASD). The aim of this research is to investigate playing as a methodology of teaching and learning for the student in the ASD child education. The methodological path developed through a literature review in the SCIELO and LILACS databases. The investigated works were selected articles published in portuguese in the period comprised between 2010 and 2015, using the keywords: autism, playing, school inclusion and child education. Upon the review it was possible to realize that there isn't a significant number of works that specifically debate playing as na action for the inclusion of ASD students in child education classes. From these data we perceived that in the current school scenario materials and pedagogical practices that help the teaching practice on the inclusion of students in the ASD in the child education are necessary.

Keywords: Autism spectrum disorders; Inclusion; Playing, Child education.

1 Mestranda do Programa de Mestrado Profissional do Ensino em Ciências da Saúde e do Meio Ambiente - UniFOA. Pesquisadora na área de educação inclusiva e intervenção motora e pedagógica nos Transtornos do Espectro do Autismo. (TEA).

2 Docente do Programa de Mestrado Profissional do Ensino em Ciências da Saúde e do Meio Ambiente, UniFOA. Doutor em Educação. 


\section{INTRODUÇÃO}

O presente trabalho emerge de uma dissertação de mestrado na área de ensino e, simultaneamente, do interesse pelo aumento de casos de crianças diagnosticadas autistas que estão sendo inseridas nas escolas regulares. O Censo Escolar do Ministério da Educação indica aumento no número de matrícula desses alunos no país ao longo dos anos, especialmente em escolas da rede municipal de ensino.

Cabe ressaltar que o termo, neste estudo, é concebido como Transtornos do Espectro do Autismo (TEA), sendo esta classificada no DSM-5, categoria enquadrada nos Transtornos de Neurodesenvolvimento (APA, 2013). Para De Paula Nunes, De Azevedo e Schmidt (2013, p. 558), “o TEA é definido como um distúrbio do desenvolvimento neurológico, que deve estar presente desde a infância, apresentando déficits nas dimensões sociocomunicativa e comportamental”.

Sabendo que o direito de pessoas com necessidades especiais à matrícula em escolas regulares no Brasil é garantido por lei desde a Constituição de 1988, percebemos que ainda é um desafio para os docentes. Tratando-se de alunos com TEA o desafio se faz ainda maior.

Em 1943, foram apresentados por Leo Kanner os primeiros estudos e levantamentos sobre o TEA, e hoje, após 75 anos de investigação desde a sua descoberta, ainda há pouca publicação e pesquisa científica no Brasil relacionada a portadores do transtorno, principalmente no que diz respeito à sua escolarização (DE MENEZES, 2012).

O autor ainda considera que a referida pesquisa traz à luz o processo de ensino e aprendizagem que envolve crianças no TEA inseridas em turmas regulares de educação infantil.

Assim, a relevância do estudo se justifica pelo número crescente de matrículas de crianças no transtorno nas escolas regulares (DE MENEZES, 2012; DE PAULA NUNES, DE AZEVEDO E SCHMIDT, 2013) e, o desafio para os educadores no que diz respeito a participação desses discentes nas atividades escolares e aprendizagens.

As características dos alunos no TEA surgem como principal desafio para os docentes, exigindo o desenvolvimento de estratégias de ensino que favoreçam a inclusão destes educandos no cotidiano das escolas.

Nesta linha de pensamento, se faz necessário que haja a necessidade precoce de estimulação destes alunos nas áreas da linguagem e interação social, além de ajustes comportamentais e sensoriais. Portanto, existe a prioridade de uma intervenção no referido nível de ensino, na tentativa de minimizar os impactos negativos do espectro do autismo, visando preservar ao máximo as perspectivas positivas por toda a vida destas crianças (GIKOVATE, 2004).

Dessa forma, quanto maior o conhecimento e competência dos docentes sobre o TEA, maior a pró-atividade desses na deteç̧ão dos sinais manifestados no TEA, bem como no acompanhamento do tratamento, se já foi instituído.

Segundo Camargo e Bosa (2012), é importante ressaltar que o papel de fechar diagnóstico é prerrogativa legal de neuropediatras e não de docentes. Entre outras, também é função dos docentes detectar problemas em salas de aula, além de possuir estratégias de ensino. Para isso esses profissionais precisam conhecer as características das crianças no TEA.

Diante do exposto alguns questionamentos remetem a pensar: Se for considerado que a educação infantil é um espaço em potencial que favorece a intervenção de alunos no TEA, quais estratégias metodológicas potencializam tais intervenções? Em decorrência da faixa etária dos alunos da educação infantil o brincar seria uma estratégia metodológica a ser considerada? 
Portanto, cabe ressaltar que esta pesquisa tem como objeto de estudo o brincar direcionado e mediado, uma vez que é conceituado como a linguagem universal da criança e ferramenta pedagógica importante para estimular as áreas deficitárias do autista (MATURANA, 2014) com embasamento na perspectiva teórica do desenvolvimento humano (VIGOTSKY, 2008).

Dessa forma, o objetivo da pesquisa é investigar o brincar como uma metodologia de ensino e aprendizagem para o aluno no TEA dentro da educação infantil.

\section{METODOLOGIA}

Este trabalho foi realizado em conformidade com normativas regulamentares referentes da pesquisa bibliográfica (GIL, 2002), por meio da revisão de literatura. Para tanto, foram utilizados para a busca dos artigos científicos as bases de dados SCIELO (Scientific Eletronic Library Online) e LILACS (Literatura Latino-Americana e do Caribe em Ciências da Saúde). Como estratégia para selecionar os textos, realizaram-se duas leituras, sendo a primeira dinâmica, incluindo palavras-chave, título, particularidades da autoria e suas instituições, resumo e conclusões. A segunda leitura caracterizou-se por uma dimensão maior com interpretação detalhada do texto completo, a fim de consolidar o entendimento das ideias e opiniões expostas pelos autores a respeito do assunto em tela. Ressaltamos que, no primeiro momento foram encontrados treze trabalhos na ScIELO e 37 no LILACS, totalizando cinquenta estudos. Na segunda leitura foram descartados os artigos repetidos e os estudos que não dialogavam com a referida temática, permanecendo um total de nove artigos para análise e debate.

Para a utilização dos artigos na presente pesquisa, dois critérios de inclusão foram previamente estabelecidos. O primeiro, a pertinência quanto ao contexto do objeto e dos objetivos da pesquisa, tomando-se como base os seguintes descritores: educação infantil, brincar e inclusão. Cabe ressaltar que, a busca foi realizada no cruzamento com o termo autismo e só foram incluídos se o estudo apresentasse os termos articulados. O segundo, artigos em português com limite temporal definido pelo período compreendido entre 2010 e 2015.

\section{REVISÃO DE LITERATURA}

\section{1 Compreendendo a dialética inclusão / exclusão}

Na intenção de problematizar as questões relativas aos alunos com TEA, torna-se relevante inicialmente discutir o que concebemos como exclusão neste estudo.

Para Sawaia (2009) compreender os processos de exclusão perpassa pelo debate entorno das desigualdades sociais. A autora salienta que, ao iniciarmos os estudos acerca dos processos de exclusão e os percursos históricos pela luta da inclusão, devemos considerar as questões éticas e políticas na tentativa de compreensão o binômio exclusão/ inclusão. A autora reitera que estes processos seriam a legitimação que fundamenta os discursos referentes a tais processos na sociedade atual.

As reflexões de Foucault (2001) nos auxiliam a perceber como a sociedade, no desenvolvimento da assepsia social forjou dispositivos de controle, dentre eles os processos de normalização: processos disciplinadores que a partir da norma classificam e hierarquizam atitudes, comportamentos, etnias, dentre outros.

Tais pressupostos nos servem de referência na argumentação em favor da ideia de que a inclusão, seja ela social ou educacional, é um processo de disciplinarização dos excluídos, sendo assim, um processo de controle social e manutenção da ordem na desigualdade. 
Nessa linha de pensamento, Castel (1998) menciona que o binômio exclusão/ inclusão é a base fundamental sobre a qual a sociedade atual e se estrutura, pois sob ele se organiza um discurso de coesão (inclusão). Porém, simultaneamente, os atos e comportamentos reforçam as fraturas sociais e as exclusões que nos deparamos cotidianamente nas escolas brasileiras, por exemplo: ao mesmo tempo que nossas leis exigem a inclusão de alunos com necessidades especiais na escola, nos deparamos cotidianamente com uma estrutura (arquitetônica e humana) que não atende as demandas destes sujeitos. O que transparece é que parece que estamos em busca de um conceito capaz de dar conta das contradições e complexidades exclusórias como situações de "participação excludente”, “inclusão perversa ou marginal” e “exclusão integrativa” (SAWAIA, 2001).

Santos (2002) recomenda a compreensão deste movimento, que só adquire sentido quando recheado com a vida pulsante nos diferentes contextos históricos. Portanto, é preciso realizar pesquisas com aqueles que estão instituídos sujeitos desqualificados socialmente (deixando-se ser ou resistindo), isto é, com aqueles que estão incluídos socialmente pela exclusão dos direitos humanos, para ouvir e compreender os seus brados de sofrimento.

Diante destas inquietações, Sawaia (2009) reitera que, nasce o sofrimento ético-político, retratando as vivências cotidianas das questões sociais dominantes, especialmente a dor que surge da situação social de ser tratado com inferior, subalterno, sem valor, apêndice inútil da sociedade. Tal sentimento emerge do impedimento de desenvolver, mesmo que uma pequena parte, o seu potencial humano (em virtude da natureza restritiva das circunstancias em que vive). E o mais importante, na gênese deste sofrimento está a consciência do sentimento de desvalor, da deslegitimidade social e do desejo de ser humano.

Assim, esta pesquisa toma para si este sentimento ético-político que nos impulsiona a mergulhar sobre as questões e reflexões desta temática e seus desafios de incluir o aluno no TEA.

Ao analisar o percurso histórico e social da Educação Especial é possível perceber que as ideias dominantes sobre as pessoas com necessidades especiais se pautaram em pressupostos excludentes, que as consideravam como incapazes relegadas ao desprezo, vivendo a margem de tudo que se achava produtivo e eficiente. Ao refletirmos sobre como a sociedade compreende o "diferente" e como ela própria construiu culturalmente respostas a estas diferenças, nos permite entender seus modos de organização e estruturação de leis, papéis, políticas e trabalho que se perpetuaram, consolidando em ideais dominantes de superioridade do normal padronizado sobre o diferente, considerado inferior.

Ao mesmo tempo em que o ideal da inclusão se globaliza e se torna pauta de discussão obrigatória para todos os interessados nos direitos dos alunos com necessidades educacionais especiais, são renovadas velhas controvérsias, que estavam também presentes no ideário da integração escolar, e que se referem às formas de efetivá-la.

Mantoan (2005, p. 316) aponta os seguintes conflitos acerca da inclusão escolar de alunos com necessidades educacionais especiais:

\footnotetext{
a) a inclusão é para todos, ou só para alguns?; b) a inclusão significa colocação integral na classe comum ou pode-se combinar a colocação na classe comum com situações especializadas de aprendizagem?; c) a inclusão prioriza a aprendizagem social e as amizades ou o desempenho acadêmico bem-sucedido?; d) a inclusão será prejudicial ou positiva para os alunos sem limitações?; e) as evidências empíricas sustentam ou não a inclusão?
}

Em resumo, ao longo dos últimos trinta anos, tem-se assistido a um grande debate acerca das vantagens e desvantagens, antes, da integração escolar, e, mais recentemente, da inclusão escolar. A questão sobre qual é a melhor forma de educar crianças e jovens com necessidades educacionais especiais não tem resposta ou receita pronta. Na atualidade, as propostas variam desde a ideia da inclusão - posição que defende que todos os alunos devem ser educados apenas e só na classe da escola regular - até a ideia de que a diversidade de características implica a existência e manutenção de um contínuo de serviços e de uma diversidade de opções. 


\section{2 O brincar como metodologia para o desenvolvimento e aprendizagem social.}

Na perspectiva teórica histórico-cultural, considera-se que o processo de aprendizagem emerge de sua relação com o contexto social e histórico em que está inserido. Portanto, a criança quando brinca e manipula um objeto, está em pleno aprendizado e, diante de um processo de desenvolvimento afetivo, social, cultural e motor. Considerando que o brinquedo emerge de uma produção cultural, Mello e Farias (2010) afirmaram que o desenvolvimento deixa de ser natural e passa a ser cultural, social e historicamente condicionado, pois foi produzido por sujeitos encarnados, que emergem de um processo de enação: passado, presente e futuro (NAJMANOVICH, 2001).

O aprendizado não emerge apenas de uma auto-reflexão da criança, mas de um processo de relação ou interação com um adulto ou criança mais experiente, portanto, todas as relações sociais são pedagógicas e importantes. Porém, há uma diferença das relações pedagógicas apreendidas institucionalmente, pois são sistematicamente mediadas por um profissional capacitado para dirigi-las. Neste sentido, Vigotsky (2010) ressalta que:

Pela sua importância, este processo de aprendizagem, que se produz antes que a criança entre na escola, difere de modo essencial do domínio de noções que se adquirem durante o ensino escolar. Todavia, quando a criança com suas perguntas, consegue apoderar-se dos nomes dos objetos que a rodeiam, já está inserida numa etapa específica da aprendizagem. Aprendizagem e desenvolvimento não entram em contato pela primeira vez na idade escolar, portanto, estão ligados entre si desde os primeiros dias de vida da criança. (VIGOTSKY, 2010, p. 110).

O desenvolvimento, segundo a teoria histórico-cultural, se dá como resultante de dois processos, o de maturação e o da aprendizagem. A maturação tem a função de preparar para a aprendizagem, enquanto a aprendizagem estimula e impulsiona o desenvolvimento. Formula-se que o desenvolvimento é aprendizagem, no entanto, é bem mais do que isso, a aprendizagem particular permite o desenvolvimento geral, isto é, o desenvolvimento sempre estará à frente da aprendizagem como estrutura mais complexa que se desenvolve inteiramente.

O desenvolvimento deve atingir uma determinada etapa, com consequência a maturação de determinadas funções, antes de a escola fazer a criança adquirir determinados conhecimentos e hábitos. O curso do desenvolvimento precede sempre o da aprendizagem. A aprendizagem segue sempre o desenvolvimento. (VIGOTSKY, 2006).

Segundo Vigotsky, Leontiev e Luria (2006), a referida concepção não permite colocar a função que pode desempenhar no desenvolvimento, a aprendizagem e a maturação das funções ativadas no curso da aprendizagem. O desenvolvimento e a maturação destas funções representam um pressuposto e não o resultado da aprendizagem. A aprendizagem é uma super-estrutura do desenvolvimento, e essencialmente existem intercâmbios entre os dois momentos. Desta forma, pode-se perceber que os bebês são completamente dependentes dos adultos que os cercam para desenvolver-se e adaptar-se cultural e socialmente no meio em que vivem e, quando não inseridos ou recebidos de forma adequada, encontrarão sem dúvida grandes obstáculos no percurso do seu pleno desenvolvimento.

Mukhina (1996) enfatizou que a criança durante toda a vida necessita do adulto, seja para utilizar objetos, pensar, falar, andar, sentir e se controlar. Todas estas ações são mediadas, não só as ações práticas, mas também os atos psíquicos são resultados das aprendizagens advindas de adultos.

Bagarollo, Ribeiro e Panhoca (2013) apontaram que é possível por intermédio da atividade do brincar desenvolver a interação social favorável ao desenvolvimento do imaginário, da ação de imitar e o uso cultural do brinquedo. Neste sentido, a mediação adulta permite atribuir significados às ações da criança também no TEA. Assim, a atuação do adulto sobre a vida de uma criança torna-se imprescindível. Somente por meio da convivência em sociedade e da função do mediador do adulto ou, até mesmo por outras crianças com mais experiência, é que a criança poderá apropriar-se de condições que favoreçam o seu desenvolvimento enquanto ser social. 
Sanini, Sifuentes e Bosa (2013), ao avaliarem o desenvolvimento da interação social no contexto da inclusão escolar, por meio da atividade de brincar, evidenciaram que brincadeiras livres tendem a ser mais duradouras e espontâneas, se comparadas às dirigidas. Diante do exposto, pode-se afirmar que as instituições de educação infantil possuem um importante papel formador do ser humano, ocupando um patamar privilegiado no desenvolvimento infantil.

A educação de crianças - ou seja, a forma como organizamos as experiências que propomos às crianças - assume o caráter de impulsionadora do desenvolvimento infantil. Com esses pressupostos, falamos em educação desenvolvente, ou seja, uma educação intencionalmente organizada para impulsionar positivamente o desenvolvimento infantil. (MELLO; FARIAS, 2010, p. 55).

É fundamental ressaltar que as práticas educativas contribuem para apropriação dos conhecimentos humanos adquiridos historicamente. Deste modo, é importante também que o professor saiba propiciar à criança a condição necessária para que sua intervenção seja efetiva. Para isso, ele precisa proporcionar e intervir nas atividades infantis, para que venham a ser ricas de possibilidades para o desenvolvimento da criança.

O conceito proposto por Vigostky (2008), denominado zona de desenvolvimento real (ZDR), são ações em que a criança consegue realizar sem a ajuda de um adulto, por corresponderem a conceitos já internalizados pelo indivíduo, ao que denominou nível de desenvolvimento real. Por outro lado, o nível de desenvolvimento potencial são tarefas que somente serão realizadas com a ajuda de outras pessoas. Portanto, a zona de desenvolvimento proximal corresponde a distância entre o nível de desenvolvimento real, que se costuma determinar por meio da solução independente de problemas, e o nível de desenvolvimento potencial, determinado por meio de solução de problemas sob a orientação de um adulto ou em colaboração de colegas mais capazes. É na zona potencial de desenvolvimento que o professor deve atuar, com objetivo de colaborar com a viabilização de processos que estão amadurecendo nos alunos. Entretanto, não basta submeter o aluno a condições ideais de estudo e esperar que ele faça o caminho sem orientação, O educador, deve procurar intervir sempre que necessário para a elevação da qualidade da aprendizagem.

\section{APRESENTAÇÃO E DISCUSSÃO DOS RESULTADOS}

A revisão da literatura realizada nas bases de dados das plataformas Scielo e Lilacs, permitiu perceber a insuficiência de abordagens que pontualmente tratam da inclusão de alunos no TEA em turmas de educação infantil, bem como a atividade de brincar como metodologia de desenvolvimento social no contexto escolar.

Para melhor facilitar a leitura e a compreensão dos resultados, a discussão será desenvolvida em três subtemas: O primeiro sobre os estudos referentes o TEA na educação infantil, o segundo sobre o brincar no TEA e o terceiro sobre a inclusão escolar de crianças no TEA e a formação de professores.

\section{EDUCAÇÃO INFANTIL E O TRANSTORNO DO ESPECTRO DO AUTISMO}

A atividade de brincar implicada na promoção do desenvolvimento de habilidades motoras e relacionais foi reconhecida e evidenciada no âmbito da educação infantil por meio de estudo de casos conduzido por Chicon, Sá e Silva (2013). Esse reconhecimento e evidência reúnem importância adicional tendo em vista a natureza prática do trabalho, além da fundamentação teórica.

A pesquisa de Sanini, Sifuentes e Bosa (2013) foi utilizada como embasamento para tentar provocar uma discussão mais ampla em torno do impacto das atividades de brincar no contexto da inclusão escolar no cenário da educação infantil. Os autores abordaram o brincar evidenciando a maior eficiência quando tal ação se dá de forma livre, pois apresentam tendência a perpetuar por mais tempo, além de serem espontâneas em relação às atividades. 
Os resultados da pesquisa investigativa conduzida por Sanini, Sifuentes e Bosa (2015), sobre as relações de professoras de educação infantil com suas atribuições e com os alunos, mostraram que tais professoras reconhecem o potencial dos alunos, mas a condição de limitação da escolaridade não colabora para que essas professoras elevem suas expectativas e autoconfiança, o que pode significar uma inadequada autoestima, o que de certa forma não é uma condição ideal no processo ensino-aprendizado.

Estudos conduzidos por Camargo e Bosa (2012) analisaram a competência social de criança no TEA incluída em turma regular na fase pré-escolar e apontou que a referida criança apresenta maior frequência de comportamento aceitável, cooperação e asserção social no pátio da escola, se comparada a crianças neurotípicas em situação de brincadeiras coletivas.

\section{O BRINCAR E O TRANSTORNO DO ESPECTRO DO AUTISMO}

Para Bagarollo, Ribeiro e Panhoca (2013), o valor da atividade de brincar é capaz de proporcionar o desenvolvimento de diferentes aspectos importantes na criança, em especial aquelas no TEA. Entretanto, essa atividade, o brincar, apesar de possuir essa importância de vasta dimensão, ainda é mais utilizada em terapia e pouco no cenário escolar.

Moro e Souza (2011) afirmaram que o brincar é uma ação potencial no desenvolvimento das crianças durante a infância, fundamentalmente se considerarmos o significado de objetos, o aprendizado da linguagem e realidade de vida.

Seguindo tal premissa podemos perceber que a atividade de brincar é uma necessidade para qualquer criança em desenvolvimento infantil, sendo ela neurotípica ou não. Além disso, em indivíduos com necessidades específicas, a atividade de brincar além de contribuir para o desenvolvimento da criança, também pode servir como procedimento de diagnóstico em crianças no TEA (SOBOIA, 2015).

Apesar da importância da atividade do brincar, sobre diversos aspectos do desenvolvimento infantil, para crianças de um modo em geral e especificamente para aquelas que possuem o TEA, o trabalho comparativo de Klinger e Souza (2015) evidenciou vantagens e também desvantagens da funcionalidade da mencionada atividade. Os resultados dessa pesquisa experimental comprovam que por mais eficiente que seja qualquer metodologia, essa invariavelmente nunca é isenta de algum efeito indesejável.

Sandroni, Ciasca e Rodrigues (2015) e Sá, Siquara e Chicon (2015) consideram a importância do brincar para os estímulos psicomotores seriados em crianças com necessidade educativa específica, pois além de estimular a psicomotricidade, também possui significativo estímulo para outras aprendizagens. Pode-se inferir então, que a atividade de brincar contribui com o desenvolvimento pleno: físico e cognitivo. Por isso, pode ser considerado como um procedimento relevante para ações de inclusão em crianças neurotípicas ou portadores de necessidades específicas.

Na educação infantil, a criança precisa ser estimulada na zona proximal de desenvolvimento, que corresponde a distância entre o nível real (capacidade já adquirida para realização de atividades) e o nível potencial (realização de tarefa sob orientação de um adulto ou companheiros mais capazes), para auxiliar na viabilização dos processos que estão em amadurecimento nos alunos. Não basta submeter os alunos às condições ideais e esperar que ele faça sozinho, o professor deve procurar mediar sempre que necessário para a qualidade e garantia da aprendizagem.

Sendo assim, os poucos trabalhos que consideram a ação do brincar, não a trata como uma ferramenta de educação intencionalmente organizada para impulsionar o desenvolvimento infantil e, ainda não considera os processos de internalização, que é o resultado das experiências vividas por meio das brincadeiras que impulsionam a criança para resolução de problemas específicos de suas etapas de desenvolvimento, pois para a referida teoria, a brincadeira estabelece a mediação do contexto social com o desenvolvimento infantil. 


\section{CONSIDERAÇÕES FINAIS}

Diante dos artigos analisados percebemos que a inclusão não precisa ser compreendida como uma dicotomia entre inclusão/exclusão, classes especiais ou salas regulares. Os achados da pesquisa apontaram que o brincar vem sendo utilizado como recurso de promoção social em indivíduos no TEA. Porém, está sendo utilizado predominantemente em terapias multiprofissionais, e pouco explorado no cenário escolar. Por fim, observamos a necessidade de se ampliar a discussão sobre práticas e materiais pedagógicos que auxilie a ação docente na educação infantil, amparando a inclusão de educandos no TEA.

A revisão integrativa de literatura realizada nas bases de dados das plataformas Scielo e Lilacs, permitiu perceber que não há um número significativo de trabalho que pontualmente tratam da inclusão de alunos no TEA em turmas de educação infantil, bem como pesquisas em que a atividade de brincar cuja metodologia de desenvolvimento social no contexto escolar, tivesse como centralidade perspectiva da teoria histórico-cultural.

Tais evidências (a ausência de um número significativo de estudos que mencionem a necessidade da intervenção na educação infantil e estudos que tenham a teoria histórico-cultural como fundamentação teóricometodológica), justificam a elaboração do produto proposto por esta dissertação (cartilha digital, em formato de e-book, com orientações e informações acerca dos Transtornos do Espectro do Autismo, tendo a teoria de Vigotsky como centralidade), pois consideramos que o brincar influi significativamente tanto no desenvolvimento pré-existente como também na aprendizagem, que devem ser entendidos como dois processos indissociáveis, pois são interligados e interdependentes (VIGOTSKY, 2008). 


\section{REFERÊNCIAS}

BAGAROLLO, M. F.; RIBEIRO, Vanessa Veis; PANHOCA, Ivone. O brincar de uma criança autista sob a ótica da perspectiva hitórico-cultural. Revista brasileira de educação especial, v. 19, n. 1, p. 107-120, março, 2013.

BARBA, P. C. S. D.; MINATEL, M. M. Contribuições da terapia ocupacional para a inclusão de crianças com autismo. Cadernos de terapia ocupacional, v. 21, n. 3, 2013.

BARBOSA, A. J. G.; CONTI, M. Formação em psicologia e educação inclusiva: um estudo transversal. Revista Psicologia Escolar e Educacional, v. 15, n. 2, p. 231-234, dezembro, 2011.

BASTOS, M.B., KUPFER, H. A escuta de professores no trabalho de inclusão escolar de crianças psicóticas e autistas. Revista Estilos Clín., v. 15, n. 1, p. 116-125, 2010.

BENITEZ, P.; DOMENICONI L. Capacitação de agentes educacionais: proposta de desenvolvimento de estratégias inclusivas. Revista brasileira de educação especial, v. 20, n. 3, p. 371-386, setembro, 2014.

CAMARGO S. P. H.; BOSA, C. Competência social, inclusão escolar e autismo: um estudo de caso comparativo. Revista psicologia teoria e pesquisa, v. 28, n. 3, p. 315-324, set., 2012.

CASTEL, R. As metamorfoses da questão social: uma crônica do salário. Petrópolis: Vozes. 1998.

CHICÓN, J. F.; SÁ, M. C. S.; SILVA, A. Atividades lúdicas no meio aquático: possibilidades para inclusão. Rev. Movimento, v. 19, n. 2, p. 103-122, abr-jun, 2013.

DE MENEZES, Adriana Rodrigues Saldanha. Inclusão escolar de alunos com autismo: quem ensina e quem aprende? 2012. 160 f. Dissertação de Mestrado - Faculdade de Educação, Universidade do Estado do Rio de Janeiro, Rio de Janeiro, 2012.

DE PAULA NUNES, Débora Regina; DE AZEVEDO, Mariana Queiroz Orrico; SCHMIDT, Carlo. Inclusão educacional de pessoas com Autismo no Brasil: uma revisão da literatura. Revista Educação Especial, v. 26, n. 47, p. 557-572, 2013.

FAVORETTO, N. C., LAMÔNICA, D. C. Conhecimentos e necessidades dos professores em relação aos transtornos do espectro do autístico. Rev. bras. educ. espec., v. 20, n. 1, p. 103-116, jan.-mar, 2014.

FOUCAULT, M. O nascimento da clínica. Rio de Janeiro: Forense Universitária, 1963/2001.

GIACONI, C; RODRIGUES, M. B. Organização do espaço e do tempo na inclusão de sujeitos com autismo. Revista Educação Real, v. 39, n. 3, p. 687-705, set., 2014.

GIKOVATE, C. Diagnóstico e intervenção no transtorno do espectro do autismo. Rio de Janeiro: EdUERJ. 2004.

GIL, A. C. Métodos e técnicas de pesquisa social. São Paulo: Atlas, 2002.

GOMES, C. G. S.; MENDES, B. Escolarização Inclusiva de alunos com autismo na rede municipal de ensino de Belo Horizonte. Revista Brasileira de Educação Especial., v. 16, n. 3, p. 375-396, set-dez, 2010.

KLINGER, E. F.; SOUZA, A.P. Análise clínica do brincar de uma criança de uma criança do espectro autista. Rev. Dist. Comun. v. 27, n. 1, p. 15-25, março, 2015.

LEMOS, E. L. M. D.; SALOMÃO, N. M. R; RAMOS, C. S. A. Inclusão de crianças autistas: um estudo sobre interações sociais no contexto escolar. Rev. bras. educ. espec., v. 20, n. 1, Marília, jan-mar, 2014. 
MANTOAN, M. T. E. A hora da virada. In: MANTOAN, M. T. E. Revista da educação especial. Brasília: MEC\Secretaria de Educação Especial, v. 1, n. 1, out. 2005.

MATURANA, L. L. D. Educação Infantil e ethos lúdico. Revista Latinoamericana, Santiago, v. 13, n. 37, p. 85-94, 2014.

MELLO S. A.; FARIAS, M. A; A escola como lugar da cultura mais elaborada. Educação, Santa Maria, v. 35, n. 1, p. 53-68, jan/abr, 2010.

MORO, M. P.; SOUZA, D. Três análises de linguagem no autismo. Revista CEFAC, v. 13, n. 5, p. 944-955, 2011. MUKHINA, V. Psicologia da idade pré-escolar. São Paulo: Martins Fontes, 1996.

NAJMANOVICH, Denise. O sujeito Encarnado: questões para pesquisa no/do cotidiano. Rio de Janeiro: DPeA. 2001. RODRIGUES, I.; MOREIRA, D.; LERNER, G. A. Análise institucional do discurso de professores de alunos diagnosticados como autistas em inclusão escolar. Rev. Psicologia: Teoria e Prática, v. 14, n. 1, p. 70-83, abril, 2012.

SÁ, M G S; SIQUARA, Z. O; CHICON, J. F. Representações simbólicas e linguagem de uma criança com autismo no ato de brincar. Rev. Bras. Ciências do Esporte, v. 37, n. 4, p. 355-361, dezembro, 2015.

SANDRONI, G.A., CIASCA, S. M.; RODRIGUES, S. D. Avaliação da evolução do perfilmotor de pré-escolares com necessidades educativas especiais após intervenção psicomotora breve. Rev. psicoped., v. 32, n. 97, p. 4-13, 2015.

SANTOS, T. C. C.; SANTOS, M. A. Educação Inclusiva: prática de professores frente à deficiência intelectual. Dissertação (Mestrado em Educação) - Universidade Federal do Rio Grande do Norte, 2012.

SANTOS, B. S. Para uma sociologia das ausências e uma sociologia das emergências. Rev. crít. cienc. soci., 2002.

SAWAIA, B. B. (org). As artimanhas da exclusão: análise psicossocial e ética da desigualdade social. 3. ed. Petrópolis: Vozes. 2001.

O sofrimento ético-político como categoria de análise da dialética exclusão/inclusão. 3. ed. Petrópolis: Vozes. 2009.

VIGOTSKY, L. S. Aprendizagem e Desenvolvimento Intelectual na Idade Escolar. In: VIGOTSKY, L. S; LEONTIEV, A. N.; LURIA, A. R. Linguagem, desenvolvimento e aprendizagem. 11. ed. São Paulo: Ícone. 2008.

. Os princípios psicológicos da brincadeira pré-escolar. In: VIGOTSKY, L. S; LEONTIEV, A. N.; LURIA,

A. R. Linguagem, desenvolvimento e aprendizagem. 10. ed., São Paulo: Ícone. 2000. 